\title{
Transcendental leadership and organizational citizenship behavior: Investigating the role of spirituality in the workplace
}

\author{
Iman Fatollah Najarbashi* and Ali Aalikhani
}

Department of Management and Accounting, North Branch, Islamic Azad University, Tehran, Iran

\section{H R O N I C L E}

Article history:

Received January 14, 2014

Accepted 10 June 2014

Available online

June 182014

Keywords:

Transcendental leadership

Organizational citizenship

behavior

Spirituality in the workplace

\begin{abstract}
A B S T R A C T
This paper studies the relationship between transcendental leadership and organizational citizenship behavior by investigating the role of spirituality in the workplace as a mediator. The study is executed for a case study of an Iranian insurance firm located in city of Tehran, Iran. The survey uses three questionnaires for transcendental leadership, spirituality in the workplace and organizational citizenship behavior. The results indicate that there were some meaningful relationships between the components of transcendental leadership and organizational citizenship behavior and element of spirituality in the workplace and organizational citizenship behavior. In addition, the study indicates that there were positive and meaningful relationships between vision/hope/faith and spiritual traditions, between components of transcendental and spiritual rituals, between oriented leadership and ultimately transcendent and spiritual components of oriented leadership. However, the study does not find any relationship between the two components of love, friendship and leaders' spiritual growth and its subordinates and variable of oriented tradition of spirituality.
\end{abstract}

\section{Introduction}

During the past few decades, interest in Organizational Citizenship Behavior (OCB) has increased significantly (Markóczy \& Xin, 2004; Organ, 1988, 1997; Smith, 1983; Appelbaum et al., 2004). Podsakoff et al. (1997), for instance, investigated organizational citizenship behavior and the quantity and quality of work group performance and reported some strong relationship between these two items. Organizational behavior has been linked to overall organizational effectiveness and these kinds of employee behaviors yield important consequences in the workplace. OCB also plays essential role on working environment (Ashmos \& Duchon, 2000; Giacalone \& Jurkiewicz, 2003; Fernando, 2007). Karakas (2010) reviewed spirituality at work literature and investigated how spirituality could improve employees' performances and organizational effectiveness. They presented three different perspectives on how spirituality benefits employees and supported organizational performance based 
on the extant literature. They explained that spirituality could enhance employee well-being and quality of life, it could provide employees a sense of purpose and meaning at work and gives employees a sense of interconnectedness and community. The study also introduced potential advantages of bringing spirituality into the workplace.

According to Marques (2006), spirituality at work is an inside-out method; workers at various levels may help establish spirit at work. Piryaei and Zare (2013) studied the relationship between workplace spirituality characteristics and two positive work attitudes, job satisfaction and organizational commitment, considering the moderating effect of individual spirituality. They reported that workplace spirituality aspects were positively associated with job satisfaction and organizational commitment and employee's individual spirituality could moderate the number of these associations. Rego and e Cunha (2008) reported that when people experience workplace spirituality, they may feel more affectively attached to their organizations, experience a sense of obligation/loyalty towards them, and feel less instrumentally committed. Chen and Li (2013) examined different determinants considered to affect the spiritual leadership (SL) effectiveness, including one motivational mediating factor of follower's self-concepts, and two conditional factors, i.e., culture (as a macro-level factor) and managerial position (as a micro-level factor). The construct of SL was validated based on a sample comprising 591 workers from different profitable organizations in two major Chinese societies. A second sample of 122 military police in the army was also used for validation purpose. They integrated the follower's transcendental self-concepts into the existing SL framework, and validated their substantiality to leadership effectiveness.

\section{The proposed study}

This paper studies the relationship between transcendental leadership and organizational citizenship behavior by investigating the role of spirituality in the workplace as a mediator. The study is executed for a case study of an Iranian insurance firm located in city of Tehran, Iran. The study uses three questionnaires for transcendental leadership (Fry, 2005; Alexakis, 2011), spirituality in the workplace and organizational citizenship behavior (Podsakoff et al., 2000).

The questionnaire consists of three parts in Likert scale where 21 questions are associated with organizational citizenship behavior (OCB), 23 questions are devoted to transcendental leadership and 16 questions are related to spirituality in the workplace. Fig. 1 demonstrates the proposed study of this paper,

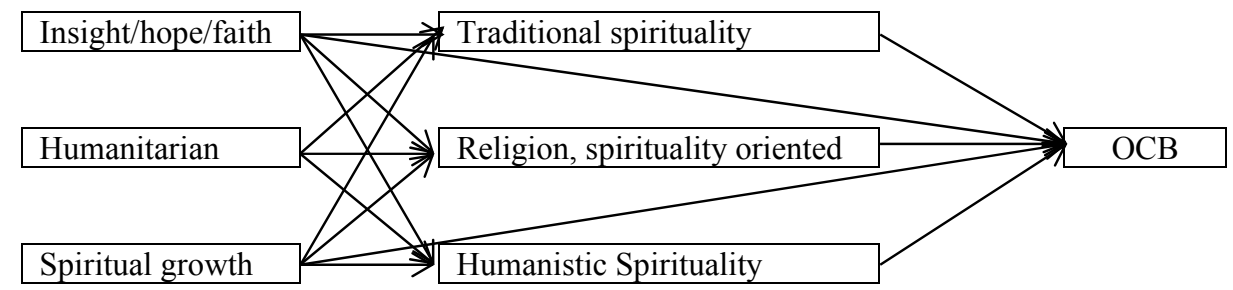

Fig. 1. The proposed study

The main hypothesis of this survey is as follows,

Main hypothesis: Transcendental leadership (Liu, 2008; Fry et al., 2005) influences on organizational citizenship behavior by emphasizing on the mediating role of spirituality in the workplace.

In order to examine the main hypothesis of this survey, we need to consider the following subhypotheses, 
1. Transcendental leadership components influence on OCB.

1.1. Insight/hope/faith influences on OCB.

1.2. Spiritual growth influences on OCB.

2. Spirituality in the workplace influences on OCB.

2.1. Traditional spirituality influences on OCB.

2.2. Religion and spirituality oriented behaviors influence on OCB.

2.3. Humanistic spirituality influences on OCB.

3. Transcendental leadership components influence spirituality in the workplace.

3.1. Transcendental leadership components influences on traditional spirituality.

3.1.1 Insight/hope/faith influences on traditional spirituality.

3.2.1 Humanistic spirituality influences on traditional spirituality.

3.2.3 Spiritual growth influences on traditional spirituality.

3.2. Transcendental leadership components influence on religion and spirituality oriented.

3.2.1 Insight/hope/faith influences on religion and spirituality oriented.

3.2.2 Humanistic spirituality influences religion and spirituality oriented.

3.2.3 Spiritual growth influences on religion and spirituality oriented.

3.3. Transcendental leadership components influence on humanistic spirituality.

3.3.1 Insight/hope/faith influences on humanistic spirituality.

3.3.2 Humanitarian influences on humanistic spirituality.

3.3.3 Spiritual growth influences on humanistic spirituality.

The proposed study has been accomplished among randomly selected people who work for an insurance firm named "Dana Insurance firm" located in city of Tehran, Iran. The sample size is calculated as follows,

$n=\frac{N \times z_{\alpha / 2}^{2} \times p \times q}{\varepsilon^{2} \times(N-1)+z_{\alpha / 2}^{2} \times p \times q}$,

where $N$ is the population size, $p=1-q$ represents the yes/no categories, $z_{\alpha / 2}$ is CDF of normal distribution and finally $\varepsilon$ is the error term. Since we have $p=0.5, z_{\alpha / 2}=1.96$ and $N=850$, the number of sample size is calculated as $n=265$. Cronbach alphas for transcendental leadership, spirituality in the workplace and organizational citizenship behavior are $0.85,0.843$ and 0.71 , respectively.

\subsection{Personal characteristics of the participants}

In our survey, $107(40.7 \%)$ of the participants were female and $155(58.9 \%)$ of them were male. Fig. 2 demonstrates the summary of other personal characteristics of the participants.

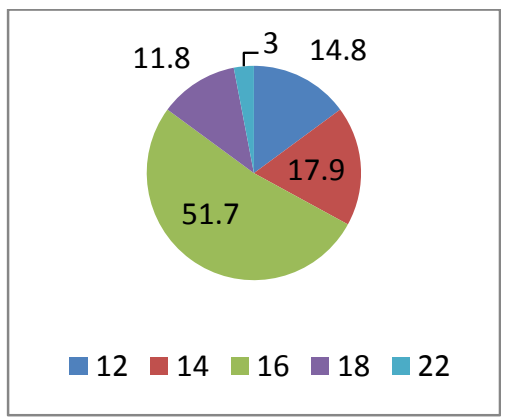

Years of education

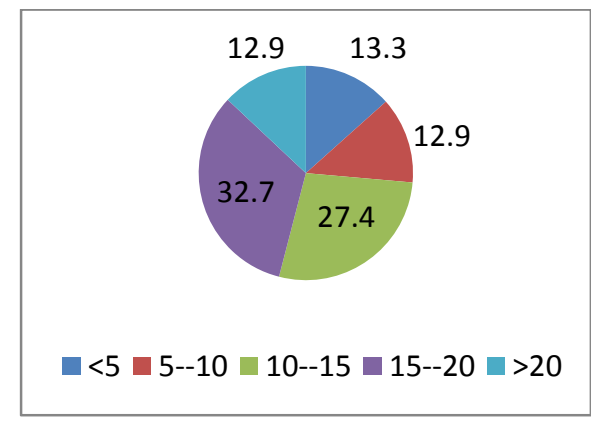

Years of education

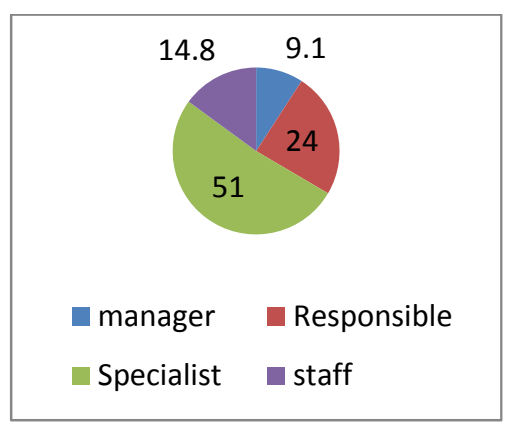

Job position

Fig. 2. Personal characteristics of the participants 
As we can observe from the results of Fig. 2, most participants hold good educational background and they had well above five years of job experiences. Table 1 demonstrates the summary of some basic statistics associated with the proposed study.

\section{Table 1}

The summary of mean, standard deviation and Kolmogorov-Smirnov tests

\begin{tabular}{lccccc}
\hline Variable & Number & Mean & Standard deviation & KZ & P-Value \\
\hline Transcendental leadership & 263 & 3.14 & 0.61 & 0.71 & 0.695 \\
Organizational citizenship behavior & 263 & 3.66 & 0.31 & 0.623 & 0.833 \\
Spirituality in the workplace & 263 & 4.07 & 0.44 & 0.947 & 0.331 \\
\hline
\end{tabular}

The results of Table 1 show that all components of the survey are normally distributed and we can use parametric tests to examine the hypotheses of the survey. The proposed study of this paper uses structural equation modeling to do the investigation.

\section{The results}

In this section, we present details of our findings on testing various hypotheses of the survey. As explained earlier, the study uses structural equation modeling. Table 2 shows details of some statistical observations on three questionnaires of the study.

Table 2

The summary of some statistical observation on the SEM implementation

\begin{tabular}{lcccccc}
\hline Variable & RMSEA & Chi-Square/df & GFI & AGFI & CFI & IFI \\
\hline Transcendental leadership & 0.000 & 2.65 & 0.92 & 0.87 & 0.92 & 0.92 \\
Organizational citizenship behavior & 0.000 & 2.89 & 0.91 & 0.87 & 0.90 & 0.91 \\
Spirituality in the workplace & 0.000 & 2.95 & 0.91 & 0.86 & 0.91 & 0.91 \\
\hline RMSEA = Root-mean-square error of approximation AGFI = Adjusted goodness-of-fit index CFI & & &
\end{tabular}

As we can observe from the results of Table 2, all statistical observations are within the acceptable levels of we may rely on the results of SEM implementation.

Table 3

The summary of testing hypotheses of the survey

\begin{tabular}{|c|c|c|c|c|c|c|}
\hline Variable & Standard $\beta$ & Standard error & t-value & $\mathrm{R}^{2}$ & Sig. & Result \\
\hline Insight/hope/faith influences $\rightarrow$ OC & 0.48 & 0.031 & 8.89 & 0.39 & 0.01 & Confirmed \\
\hline Spiritual growth influences $\rightarrow$ OCB & -0.16 & 0.019 & -3.41 & 0.39 & 0.01 & Confirmed \\
\hline Traditional spirituality $\rightarrow$ OCB & 0.19 & 0.021 & 4.31 & 0.39 & 0.01 & Confirmed \\
\hline Religion $\rightarrow$ OCB & 0.28 & 0.014 & 6.20 & 0.39 & 0.01 & Confirmed \\
\hline Humanistic spirituality $\rightarrow$ OCB & -0.23 & 0.015 & -5.05 & 0.39 & 0.01 & Confirmed \\
\hline Insight/hope/faith $\rightarrow$ traditional spirituality & 0.35 & 0.074 & 6.06 & 0.14 & 0.01 & Confirmed \\
\hline Humanistic spirituality $\rightarrow$ traditional spirituality & 0.05 & 0.079 & 0.55 & 0.14 & $>0.05$ & Rejected \\
\hline Spiritual growth $\rightarrow$ traditional spirituality & -0.01 & 0.074 & -0.16 & 0.14 & $>0.05$ & Rejected \\
\hline Insight/hope/faith $\rightarrow$ religion & 0.42 & 0.1 & 7.41 & 0.20 & 0.01 & Confirmed \\
\hline Humanistic spirituality $\rightarrow$ religion & 0.51 & 0.11 & -6.05 & 0.20 & 0.01 & Confirmed \\
\hline Spiritual growth $\rightarrow$ religion & 0.39 & 0.10 & 4.79 & 0.2 & 0.01 & Confirmed \\
\hline Insight/hope/faith $\rightarrow$ humanistic spirituality & 0.45 & 0.092 & 8.75 & 0.35 & 0.01 & Confirmed \\
\hline Humanitarian $\rightarrow$ humanistic spirituality & -0.78 & 0.098 & -10.24 & 0.35 & $>0.05$ & Confirmed \\
\hline Spiritual growth $\rightarrow$ traditional spirituality & 0.70 & 0.092 & 9.50 & 0.35 & $>0.05$ & Confirmed \\
\hline
\end{tabular}

\section{Discussion and conclusion}

The results of Table 3 indicate that except two cases, the effect of humanistic as well as spiritual growth spirituality on traditional spirituality, all other hypotheses of the survey have been confirmed. 
In other words, transcendental leadership components influence on OCB where the effects of Insight/hope/faith influences are positive and the effects of spiritual growth are negative. In addition, spirituality in the workplace influences on OCB where the effects of traditional spirituality and religion and spirituality oriented behaviors on OCB is positive and the effect of humanistic spirituality is negative. Next, the effect of transcendental leadership components on religion and spirituality oriented is confirmed and the effect of transcendental leadership components on humanistic spirituality has also been confirmed.

\section{Acknowledgement}

The authors would like to thank the anonymous referees for constructive comments on earlier version of this paper.

\section{References}

Alexakis, G. (2011). Transcendental leadership: the progressive hospitality leader's silver bullet. International Journal of Hospitality Management, 30(3), 708-713.

Appelbaum, S., Bartolomucci, N., Beaumier, E., Boulanger, J., Corrigan, R., Dore, I., ... \& Serroni, C. (2004). Organizational citizenship behavior: a case study of culture, leadership and trust. Management decision, 42(1), 13-40.

Ashmos, D., \& Duchon, D. (2000). Spirituality at work. Journal of Management Inquiry, 9(2), 134145.

Chen, C. Y., \& Li, C. I. (2013). Assessing the spiritual leadership effectiveness: The contribution of follower's self-concept and preliminary tests for moderation of culture and managerial position. The Leadership Quarterly, 24(1), 240-255.

Giacalone, R. A., \& Jurkiewicz, C. L. (2003). Toward a science of workplace spirituality. Handbook of workplace spirituality and organizational performance, 3-28.

Fernando, M. (2007). Spiritual leadership in the entrepreneurial business: a multifaith study. Edward Elgar Publishing.

Fry, L. W. (2005). Introduction to The Leadership Quarterly special issue: Toward a paradigm of spiritual leadership. The Leadership Quarterly,16(5), 619-622.

Fry, L. W., Vitucci, S., \& Cedillo, M. (2005). Spiritual leadership and army transformation: Theory, measurement, and establishing a baseline. The Leadership Quarterly, 16(5), 835-862.

Karakas, F. (2010). Spirituality and performance in organizations: A literature review. Journal of Business Ethics, 94(1), 89-106.

Liu, H. O. (2008). Transcendental leadership and organizational citizenship behavior: The mediating effect of spirituality in the workplace. University of Southern California.

Markóczy, L., \& Xin, K. (2004). The virtues of omission in Organizational Citizenship Behavior. university of californial.

Marques, J. F. (2006). The spiritual worker: An examination of the ripple effect that enhances quality of life in-and outside the work environment. Journal of Management Development, 25(9), 884895.

Organ, D. W. (1988). Organizational citizenship behavior: The good soldier syndrome. Lexington Books/DC Heath and Com.

Organ, D. W. (1997). Organizational citizenship behavior: It's construct clean-up time. Human performance, 10(2), 85-97.

Piryaei, S., \& Zare, R. (2013). Workplace spirituality and positive work attitudes: The moderating role of individual spirituality. Indian Journal of Economics and Development, 1(4), 91-97.

Podsakoff, P. M., Ahearne, M., \& MacKenzie, S. B. (1997). Organizational citizenship behavior and the quantity and quality of work group performance. Journal of applied psychology, 82(2), 262. 
Podsakoff, P. M., MacKenzie, S. B., Paine, J. B., \& Bachrach, D. G. (2000). Organizational citizenship behaviors: A critical review of the theoretical and empirical literature and suggestions for future research. Journal of management, 26(3), 513-563.

Rego, A., \& e Cunha, M. P. (2008). Workplace spirituality and organizational commitment: an empirical study. Journal of organizational change management, 21(1), 53-75.

Smith, C. A., Organ, D. W., \& Near, J. P. (1983). Organizational citizenship behavior: Its nature and antecedents. Journal of applied psychology, 68(4), 653. 